\title{
PRINCÍPIOS DE DESIGN PARA UM ENSINO DE CIÊNCIAS CONTEXTUALIZADO PELAS RELAÇÕES ENTRE CIÊNCIA-TECNOLOGIA- SOCIEDADE-AMBIENTE
}

\author{
Design Principles for science teaching contextualized by relations between science- \\ technology-society-environment
}

\section{Principios de diseño para la enseñanza de ciencias contextualizadas por la relación entre ciencia-tecnología-sociedad-ambiente}

\author{
Anna Cassia de Holanda Sarmento* \\ Cássia Regina Reis Muniz* \\ Ana Paula Miranda Guimarães* \\ Nei de Freitas Nunes-Neto*
}

\begin{abstract}
Resumo
A educação científica tem sido promovida de forma descontextualizada dos pontos de vista histórico, filosófico e social, além de disseminar as concepções hegemônicas acerca do consumismo e da degradação ambiental. Contudo, estamos vivendo um momento de crise ambiental, que está diretamente relacionada à forma como utilizamos a natureza. Enfrentar esse desafio e mitigar seus efeitos é modificar as relações de exploração entre os indivíduos e os recursos do planeta, sendo uma transformação profundamente ética. Para isso, utilizamos como ferramenta de ensino as questões sociocientíficas, pois, além de permitir esta abordagem contextualizada, também propicia uma abordagem inter ou transdisciplinar do tema tratado. Nossa pesquisa está fundamentada nos referenciais de design educacional e no modelo STEPWISE, além dos referenciais de história e filosofia da ciência, ciência, tecnologia, sociedade e ambiente, questões sociocientíficas e ensino de ética. O presente trabalho, visa, portanto, discutir o quadro teórico, o contexto de pesquisa e a sistematização dos princípios de design que orientarão a construção de uma sequência didática sobre aquecimento global no ensino de biologia, os quais têm o potencial de fomentar as dimensões conceituais, procedimentais e atitudinais dos conteúdos científicos para ações sociopolíticas por estudantes da educação básica.
\end{abstract}

PALAVRAS-CHAVE: Educação Ambiental. Educação CTSA. Questões Sociocientíficas

\begin{abstract}
* Doutoranda em Ensino, Filosofia e História das Ciências. Universidade Federal da Bahia (UFBA). Professora do Colégio da Polícia Militar da Bahia - Dendezeiros. Pesquisadora do LEFHBIO-UFBA. E-mail: anna.cassia01@gmail.com.

* Doutoranda em Ensino, Filosofia e História das Ciências. Universidade Federal da Bahia (UFBA). Professora do Colégio da Polícia Militar da Bahia - Dendezeiros. Pesquisadora do LEFHBIO-UFBA. E-mail: casmuniz@gmail.com.

* Doutora em Genética e Biologia Molecular (UFRGS). Professora do Instituto Federal de Educação, Ciência e Tecnologia da Bahia (IFBA)/ campus Camaçari. E-mail: apmguima@gmail.com.

* Doutor em Ecologia (UFBA). Professor Adjunto da Universidade Federal da Grande Dourados (UFGD). Pesquisador do LEFHBIO-UFBA e do INCT-INTREE/UFBA. E-mail: nunesneto@gmail.com.
\end{abstract}


Science education has been promoted in a decontextualized way from the historical, philosophical and social points of view, besides spreading hegemonic conceptions about consumerism and environmental degradation. However, we are experiencing a time of environmental crisis, which is directly related to the way we use nature. Meeting this challenge and mitigating its effects is to modify the exploitation relations between individuals and the planet's resources, being a profoundly ethical transformation. For this, we use the socio-scientific issues as a teaching tool, because, besides allowing this contextualized approach, it also provides an inter or transdisciplinary approach to the theme. Our research is grounded in the educational design frameworks and the STEPWISE model, as well as the frameworks of the history and philosophy of science, science, technology, society and the environment, socio-scientific issues and ethics teaching. Therefore, this paper aims to discuss the theoretical framework, the research context and the systematization of design principles that will guide the construction of a didactic sequence on global warming in the teaching of biology, which has the potential to foster conceptual, procedural and attitudinal dimensions of scientific contents for sociopolitical actions by students of basic education.

KEYWORDS: Environmental Education. STSE Education. Socioscientific Issues

\section{Resumen}

La educación científica se ha promovido de manera descontextualizada desde los puntos de vista histórico, filosófico y social, además de difundir las concepciones hegemónicas sobre el consumismo y la degradación ambiental. Sin embargo, vivimos un momento de crisis ambiental, que está directamente relacionado con la forma en que usamos la naturaleza. Enfrentar este desafío y mitigar sus efectos es modificar las relaciones de explotación entre los individuos y los recursos del planeta, siendo una transformación profundamente ética. Para esto, utilizamos las cuestiones socio-científicas como una herramienta de enseñanza, porque, además de permitir este enfoque contextualizado, también proporciona un enfoque inter o transdisciplinario. Nuestra investigación se basa en el marco de las investigaciones de diseño, en el STEPWISE, así como en la historia y la filosofía de la ciencia, el campo CTSA, las cuestiones sociocientíficas y la ética. Por lo tanto, discutimos el marco teórico, el contexto de investigación y la sistematización de los principios de diseño que guiarán la construcción de una secuencia didáctica sobre el calentamiento global en la enseñanza de la biología, que tiene el potencial de fomentar dimensiones conceptuales, procesuales y actitudinales de contenidos científicos para acciones sociopolíticas por estudiantes de educación básica.

PALABRAS CLAVE: Educación Ambiental. Educación CTSA. Cuestiones Sociocientíficas

\section{INTRODUÇÃO}

A educação científica, no nível médio, tem ocorrido com pouca contextualização e abordagens inadequadas acerca de questões históricas e filosóficas e das relações entre ciência, tecnologia, sociedade e ambiente (MATTHEWS, 2014; HODSON, 2004, 2013). Pensamos que uma abordagem inadequada do ensino de ciências diminui o seu potencial para o letramento científico dos estudantes, sobretudo no sentido de formá-los para tomada de decisão e ação informada. Nos currículos, a falta de politização (HODSON, 2004) e a ausência de problematização por questões sociais e ambientais (DILLON, 2012) acaba por agravar esse contexto educacional.

Neste contexto, cabe lembrar que vivemos uma época marcada por crises sem precedentes, como, por exemplo, a crise da extinção da biodiversidade (BARNOSKY et al. 2011), o aumento do consumo e da pegada ecológica (WWF 2014; BENCZE 2014), o aumento populacional que exerce forte pressão sobre os recursos ambientais (LEFF, 2006),

Revista Educação e Fronteiras On-Line, Dourados/MS, v.9, n.25, p. 183-207, jan./abr. 2019. 
e por fim, a expansão da atividade pecuária em larga escala, que tem sido a causa número um do aquecimento global antropogênico contemporâneo (GOODLAND; ANHANG, 2009). Tratam-se de crises relacionadas com a forma como as atividades socioeconômicas humanas utilizam a natureza e que se intensificam a partir dos processos educacionais que formam indivíduos indiferentes aos problemas socioambientais (HODSON, 2013) ou ainda, que contribuem diretamente para agravá-los. Em acordo com reflexões de Bencze (2014), entre outros, percebemos que a estrutura educacional hegemônica tende a manter o consumismo e a degradação ambiental, inerentes ao capitalismo neoliberal, o que, por sua vez, reforça o modelo de educação científica vigente. Contudo, os seres humanos interagem com a natureza não como indivíduos livres e totalmente independentes, mas como membros socioculturalmente situados. Desse modo, as causas fundamentais da crise ambiental não são simplesmente pertencentes à esfera do natural, mas são de natureza social, ética e política, e, assim, uma maneira de enfrentar esse desafio e mitigar seus efeitos está em modificar as relações de exploração entre os indivíduos e os recursos do planeta, que vão muito além da dimensão científica e tecnológica, sendo uma transformação profundamente ética (SHARMA, 2012).

Diante desses problemas, abordagens pedagógicas alternativas às abordagens tradicionais - focadas no professor e na memorização de informações (KRASILCHIK, 2008), buscam uma maior contextualização da ciência escolar, em termos históricos, filosóficos, epistemológicos, éticos, políticos, sociais e ambientais (CONRADO; NUNESNETO, 2018; MAIA, CABRAL, QUEIROZ, 2017).

Duas abordagens que se destacam no sentido de contextualizar o ensino e a aprendizagem em ciências são a abordagem contextualizada por história e filosofia da ciência (HFC) e aquela que leva em consideração as relações entre ciência, tecnologia, sociedade e ambiente (abordagem CTSA). Quando falamos nessas abordagens, recaímos nas lacunas pedagógicas acerca de estratégias de ensino específicas para que elas sejam efetivamente aplicadas na sala de aula. Neste sentido, as questões sociocientíficas (QSC) têm se constituído em ferramentas importantes para a construção de estratégias de ensino contextualizadas por uma abordagem CTSA (CONRADO; NUNES-NETO, 2018; HODSON, 2013, SANTOS; MORTIMER, 2009), com grande potencial para a implementação de uma abordagem contextual integrada entre HFC e CTSA. Para Conrado e Nunes-Neto (2015), o uso de QSC possibilita o trabalho com as dimensões conceituais, procedimentais e atitudinais (CPA) dos conteúdos científicos com o potencial de desenvolver uma educação voltada para ações sociopolíticas. A mobilização dos conteúdos nas dimensões CPA tem o potencial também de, a longo prazo, formar ativistas (BENCZE; ALSOP, 2014). Cabe notar que abordagens educacionais contextualizadas por HFC e CTSA também contribuem para promover um ensino e uma aprendizagem em ciências mais interdisciplinar (por já mobilizar em seu conteúdo e por solicitar que o estudante mobilize conteúdos de diferentes disciplinas acadêmicas, científicas ou humanísticas) e transdisciplinar (na medida em que busca promover ações sociopolíticas e aproximação com diferentes atores sociais, inclusive não acadêmicos $)^{1}$.

Assim, observando a importância de abordagens de ensino de ciências, e mais especificamente de biologia, contextualizadas por CTSA e orientadas por QSC, a fim de desenvolver conhecimentos, habilidades e atitudes para ação sociopolítica, o nosso

\footnotetext{
${ }^{1}$ Para os conceitos de interdisciplinaridade e transdisciplinaridade utilizados aqui, ver Tress, Tress e Van Der Valk (2003).
} 
trabalho se desenvolve no sentido de investigar, por meio de um estudo de desenvolvimento situado na sala de aula, que características (princípios de design) uma sequência didática (SD) sobre aquecimento global, no ensino médio de biologia, deve apresentar para fomentar ações sociopolíticas, a partir da mobilização de conteúdos nas dimensões conceituais, procedimentais e atitudinais (CPA). Particularmente, no presente artigo, focamos na primeira etapa (pesquisa preliminar); pretendemos apresentar um quadro teórico e a sistematização de princípios de design (PrD) usados como fundamentos para a construção de uma SD e dos seus materiais didáticos. Nas seções seguintes, apresentamos o referencial teórico metodológico que orientou parte de nosso trabalho e a sistematização dos PrD.

\section{Referencial teórico metodológico}

\section{Pesquisa de design educacional e estudos de desenvolvimento}

A pesquisa de design educacional (educational design research) é um dos referenciais teórico-metodológico que fundamentam o nosso trabalho. Visa proceder o estudo sistemático do planejamento, da implementação, da avaliação e da manutenção de intervenções educacionais como soluções para problemas complexos da prática educacional (THE DESIGN-BASED RESEARCH COLLECTIVE, 2003). O propósito é não somente desenvolver inovações educacionais ${ }^{2}$, mas também ampliar o conhecimento sobre os processos de planejamento e implementação em sala de aula e sobre as características dessas intervenções que são promissoras para o alcance de determinadas expectativas educacionais.

Um dos tipos de estudo incluídos na pesquisa de design educacional são os estudos de desenvolvimento de inovações educacionais (NIEVEEN et al., 2006). Estes estudos visam resolver problemas educacionais complexos por meio de pesquisa sistemática que possibilite a construção e a validação de princípios de design (PrD) de inovações educacionais que possam ser aplicadas em diversos contextos e envolvem desenvolvimento iterativo da inovação educacional por meio de ciclos de testes de diferentes versões ou protótipos em contextos diversos, com números crescentes de participantes (professores e alunos). Os PrD são entendidos como produtos teóricos da pesquisa de design educacional (PLOMP, 2009).

Nesse movimento iterativo, os protótipos da inovação educacional em desenvolvimento são testados e a cada ciclo de teste há um resultado parcial usado para refinar o próximo protótipo. Uma teoria de ensino específica para um dado domínio, que pode resultar de um estudo de desenvolvimento, pode ser testada por meio de outro tipo de estudo incluído na pesquisa de design educacional, os estudos de validação (NIEVEEN et al., 2006).

Estamos usando essa abordagem por meio de uma adaptação à prática social de pesquisa colaborativa que desenvolvemos, de modo a torná-la ainda mais adequada e

\footnotetext{
${ }^{2}$ Usamos o conceito de inovação educacional definido pelo grupo Colaboração em Pesquisa e Prática em Educação Científica - CoPPEC: processos intencionais, sistemáticos e participativos de produção, recontextualização e disseminação de novidades, que tenham a capacidade de promover o desenvolvimento do potencial dos atores da comunidade escolar, em termos pessoais, sociais e intelectuais. Entende-se como novidade tudo aquilo que, até então, não fazia parte da prática pedagógica da comunidade escolar (SOUZA; MUNIZ; SARMENTO, 2016).
} 
relevante para a solução de problemas reais da prática docente, pois, colocamos como requisitos necessários para a pesquisa sobre inovações educacionais a valorização do conhecimento docente e a participação ativa de professores-pesquisadores do nível de escolaridade ao qual se destina a inovação, no caso do presente estudo, a educação básica. $\mathrm{Na}$ pesquisa sobre inovações educacionais que realizamos, o professor tem, assim, lugar importante na escolha das questões de pesquisa e na avaliação da viabilidade das abordagens pedagógicas, a qual é uma condição evidentemente necessária para a solução de problemas complexos do processo de ensino e aprendizagem (ver SARMENTO et al., 2011, 2013; MUNIZ et al., 2012; GUIMARÃES et al., 2013, SÁ et al., 2015). Na dinâmica que desenvolvemos, os pesquisadores acadêmicos, por sua vez, têm papel importante na seleção de materiais de estudo, na apresentação e no esclarecimento de abordagens metodológicas, na orientação da coleta e análise dos dados, e na preparação de artigos relatando resultados da pesquisa (ALMEIDA, 2014).

Por meio do trabalho em colaboração e informados por estudos prévios, obtidos por revisão da literatura relevante, são planejadas e desenvolvidas intervenções, frequentemente na forma de SD. O estudo cuidadoso de protótipos sucessivos de intervenções em seus contextos-alvo, com o objetivo de produzir e validar princípios de planejamento (design), entendidos como generalizações de caráter teórico que, em contraste com as SD em si mesmas, têm o potencial de serem transponíveis para outros contextos de ensino.

Usamos a pesquisa de design educacional, pois é uma abordagem metodológica que, além de permitir a construção de questões de pesquisas sobre o aperfeiçoamento de inovações educacionais (El-HANI et al., 2011), possibilita uma melhor compreensão das complexas interações existentes no universo escolar e do modo como essas interações podem influenciar no processo de ensino e aprendizagem (BROWN, 1992; COBB et al., 2003), em particular quando inovações educacionais estão sendo propostas. Também contribui para aumentar o acervo teórico sobre o processo de ensino e aprendizagem (THE DESIGN-BASED RESEARCH COLLECTIVE, 2003), valorizando o conhecimento docente, uma vez que reconhece os limites da teoria educacional para a construção de intervenções situadas na sala de aula (SHAVELSON et al., 2003).

Os estudos de desenvolvimento incluem, de acordo com Plomp (2009), 3 fases: (1) pesquisa preliminar; (2) fase de prototipagem; (3) fase de avaliação. A fase de pesquisa preliminar envolve revisão da literatura e estudo do contexto real de ensino, com papel central do conhecimento docente, visando a produção de um quadro conceitual que orientará o estudo e o estabelecimento de princípios de design iniciais para a construção da intervenção. Nesta fase, há a construção da SD e dos instrumentos de coleta de dados, bem como do material instrucional que será usado nas aulas. Os $\operatorname{PrD}$ apresentam as características que orientam a construção da inovação educacional.

É importante ressaltar que, na formulação de Van den Akker (1999), os PrD têm uma dimensão substantiva, referente às características fundamentais da intervenção, e uma dimensão procedimental, referente ao conjunto de atividades que parecem ser mais promissoras para o sucesso da intervenção. São os princípios substantivos que, ao serem validados, após a avaliação de protótipos sucessivos da inovação educacional, se constituem em generalizações teóricas da pesquisa de design educacional. Os princípios procedimentais, por sua vez, variam de acordo com cada aplicação específica da inovação educacional em sala de aula. 
A fase de prototipagem engloba ciclos de investigação em que protótipos são testados e aperfeiçoados. A cada ciclo de investigação de um protótipo da inovação educacional em aperfeiçoamento, deve haver o aumento do número de participantes da pesquisa (estudantes e professores-pesquisadores). Nesta fase, é realizada uma avaliação formativa, visando análises e reflexões acerca dos resultados parciais obtidos em cada ciclo, com o intuito de melhorar e refinar a intervenção. Segundo Plomp (2009), existem muitos métodos possíveis para fazer a avaliação formativa dos quais destacamos: a avaliação por especialistas, o teste empírico com poucos participantes na pesquisa envolvendo um professor-pesquisador e uma amostra de seus estudantes numa única escola (micro-avaliação); e o teste empírico num contexto macro, envolvendo escolas diferentes e aumentando consideravelmente o número de professores-pesquisadores e estudantes participantes da pesquisa.

A fase de avaliação, ou semi-somativa, tem como propósito chegar a uma conclusão, depois de vários ciclos de investigação, acerca da capacidade da intervenção de alcançar os objetivos educacionais propostos em seu planejamento, resultando em recomendações adicionais para seu aprimoramento. É importante salientar que, ao longo das três fases, são feitas análises e reflexões sistemáticas, assim como documentação de todo o processo, a fim de não só validar os $\operatorname{PrD}$ inicialmente assumidos, mas também estabelecer novos princípios. Neste estudo, ainda não apresentamos as fases de prototipagem e de avaliação, estando a nossa pesquisa, no presente momento, situada na primeira fase da pesquisa de design educacional, pesquisa preliminar, conforme figura abaixo:

Figura 1: Demarcação do ponto em que este trabalho está inserido dentro dos ciclos da pesquisa de design 


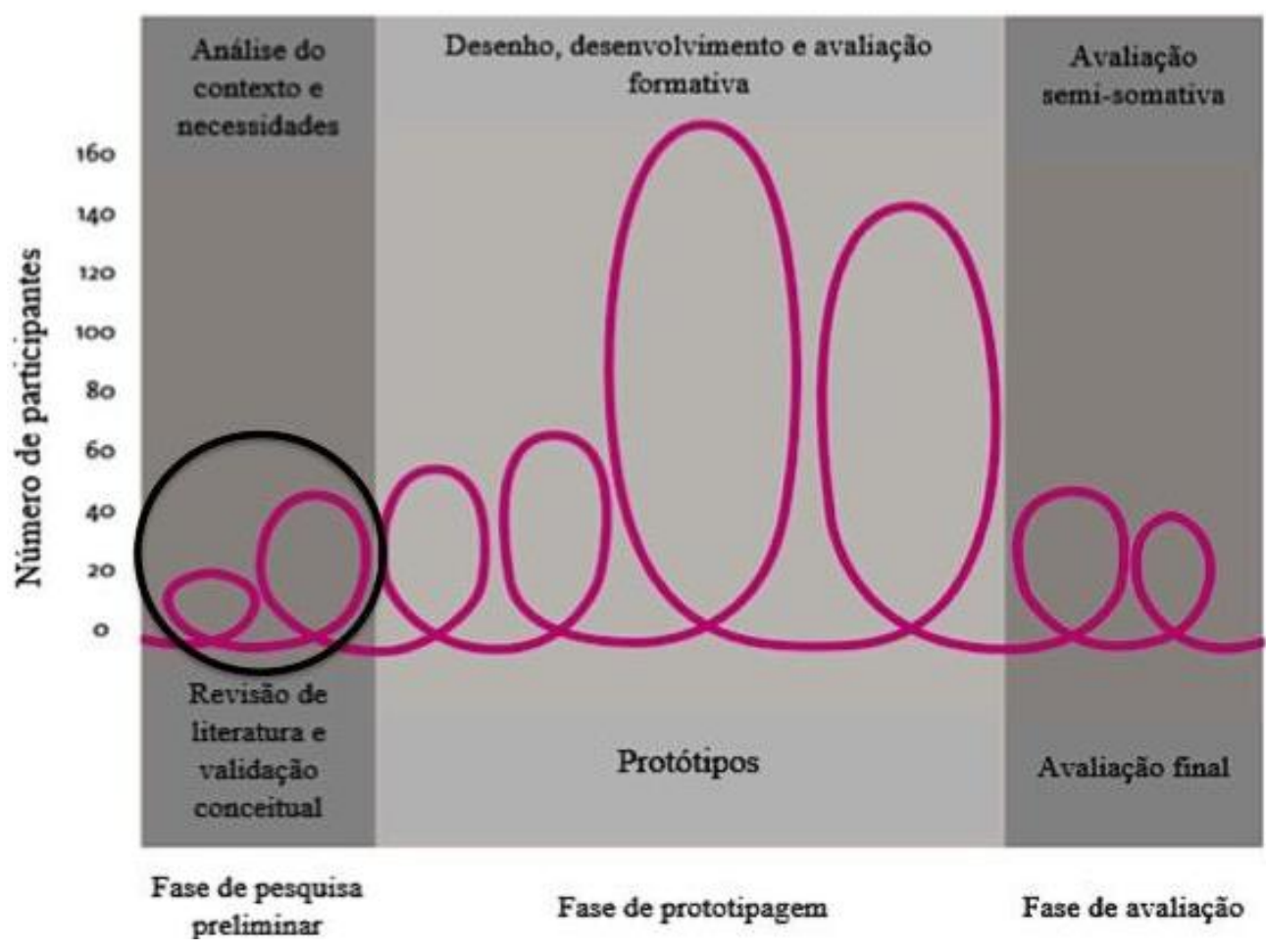

Elaborado por: adaptado de Sepulveda et al. (2016).

Os produtos teóricos da pesquisa de design educacional, os $\operatorname{PrD}$, e as evidências empíricas colhidas no processo de investigação são generalizáveis para outros contextos de ensino, numa perspectiva de generalização situada (SIMONS et al., 2003). Para que outros professores possam perceber semelhanças entre as situações de pesquisa e suas situações de ensino, em termos de variáveis contextuais compartilhadas, e se sintam motivados a usar os PrD empregados na construção de uma determinada inovação é fundamental que o contexto do estudo seja descrito de modo suficientemente rico (SARMENTO et al, 2013, SARMENTO, 2016). O uso de cadernos de campo pelos professores-pesquisadores, para registro do contexto da pesquisa, e a aplicação de um questionário socioeconômico e sociocultural torna-se, assim, um procedimento de pesquisa importante para que sejam satisfeitas condições para uma generalização situada.

\section{Formação de ativistas e o STEPWISE}

Existe uma tradição recente, mas consistente, em educação científica, para a formação de ativistas (BENCZE; ALSOP, 2009, 2014; HODSON, 2004, 2013), que se apoia, historicamente, nas contribuições da pedagogia crítica freireana. No nosso estudo, usaremos o método de ensino e de formação de ativistas, através da educação, denominado STEPWISE, adaptando-o ao nosso contexto de pesquisa, pois acreditamos, a priori, que ele está melhor alinhado aos nossos objetivos de pesquisa e está alinhado com a promoção das dimensões CPA dos conteúdos da ciência escolar ${ }^{3}$.

\footnotetext{
3 Para mais detalhes sobre We Act e STEPWISE, ver Bencze e Alsop (2014). Sobre o projeto IRRESISTIBLE, ver: http://www.irresistible-project.eu/index.php/pt/; http://www.esera2015.org/ programme/detailed-programme/parallel-sessions/?session=59 (Simpósio Responsible Research and Innovation at school: Involving Teachers and Science Exhibits).
} 
O STEPWISE 4 é um referencial teórico-metodológico, proposto por Bencze (2014), para orientar a aprendizagem em educação científica e tecnológica no sentido da realização de ativismo, visando Bem-estar para Indivíduos, Sociedades e Ambientes. Ele organiza o ensino e a aprendizagem a fim de encorajar e permitir que os estudantes tomem decisões e negociem ações para tratar de QSC, como por exemplo, o que fazer diante da crise ambiental vigente, a fim de construir um mundo melhor no que diz respeito à justiça social e à sustentabilidade ambiental. O STEPWISE apresenta uma estrutura com relações de mão dupla entre cinco domínios educacionais: (1) educação CTSA; (2) ensino de habilidades (ex. usar um microscópio e projetar um experimento); (3) ensino de produtos (ex. leis e teorias da ciência e tecnologia); (4) pesquisa dos estudantes (ex. resultados de estudos projetados por estudantes); e (5) ações CTSA (ex. petições, vídeos, campanhas de conscientização). Outra característica, integrada à educação CTSA, é o enfoque sobre HFC com vias a desenvolver uma visão mais informada e crítica da ciência.

A própria estrutura do STEPWISE para orientar a aprendizagem em ciências pode diminuir a lacuna que há entre a compreensão, algo mais teórico-abstrato, de um lado, e a ação, prática, concreta, situada, de outro lado (BENCZE; ALSOP, 2009; HODSON, 2004). Segundo Hodson (2004), é muito mais fácil para o indivíduo dizer que compreende e que se preocupa com um problema do que fazer algo acerca dele. Para o autor, certamente há um maior potencial para os estudantes implementarem conhecimentos provenientes da ciência escolar e sobre mecanismos de ação sociopolítica na vida política adulta, se eles tiverem a oportunidade de agir em situações vividas no contexto do currículo.

Podemos citar o aquecimento global e suas grandes causas, dentre elas a pecuária, como um exemplo de lacuna entre a compreensão acerca de sua problemática e a ação no sentido de minimizá-la. Muito conhecimento já foi produzido acerca do papel das atividades antrópicas nas mudanças climáticas. Segundo relatório do IPCC (2014), a atividade pecuária, sobretudo em larga escala, são a causa dominante do aquecimento do planeta desde meados do século XX. Contudo, o volume de conhecimento científico e a compreensão acerca desta questão socioambiental têm se revertido em ações pouco efetivas, nos níveis individual, local, regional, nacional e internacional, para eliminar ou ao menos mitigar as causas do problema. De acordo com Jacobi (2003), a conscientização da crise ambiental requer mais que uma mera ampliação dos conhecimentos científicos e tecnológicos; é preciso, na verdade, enfoques integradores de uma realidade contraditória e que proporciona desigualdades. Segundo Kollmuss e Agyeman (2002), muitos estudos foram conduzidos para explicar a lacuna entre o conhecimento ambiental e a ação próambiental, mas nenhuma resposta definitiva foi encontrada. Acreditamos que uma forma importante para diminuir a lacuna entre a compreensão e a ação é oferecer um ensino de biologia contextualizado por HFC e CTSA a partir de QSC a fim de formar cidadãos capazes de usar o conhecimento científico para empreender ações que possam reverter ou diminuir a crise ambiental e construir estilos de vida mais sustentáveis do ponto de vista ambiental e que, além disso, promovam justiça social. Estamos, portanto, diante do desafio de promover uma educação científica sobre aquecimento global mais crítica, com o potencial de formar indivíduos que, no seu cotidiano, sejam capazes de conduzir ações sociopolíticas, individuais ou coletivas, diretas ou indiretas, visando minimizar as causas da crise ambiental vigente. Em virtude desse desafio e diante da carência de materiais didáticos que apoiem professores na tarefa de desenvolver nos seus estudantes

\footnotetext{
${ }^{4}$ Science \& Technology Education Promoting Wellbeing for Individuals, Societies \& Environments (Ensino de Ciência e Tecnologia Promovendo Bem-estar para Indivíduos, Sociedades e Ambientes).
} 
conhecimentos, habilidades e atitudes para ação sociopolítica relativa à crise ambiental, achamos importante construir um Material Curricular Educativo para ser usado na implementação da SD. Na seção abaixo, explicitamos o que são esses materiais.

\section{Materiais Curriculares Educativos}

Os Materiais Curriculares Educativos (MCE) são um conjunto de meios, objetos e artefatos elaborados especificamente para facilitar o desenvolvimento de processos educativos (MOREIRA, 2000). Esses materiais fazem a mediação do processo de ensino e aprendizagem, facilitando a passagem de uma situação de ensino para uma situação de aprendizagem. Além disso, ainda apresentam outras funções tais como: motivação; estruturação da realidade; controle de conteúdos para ensinar; melhorar o processo de comunicação; entre outros (ARAN, 2001).

Segundo Davis e Krajcik (2005), os MCE são planejados no sentido de favorecer a aprendizagem, prioritariamente de professores, mas também de estudantes. De acordo com Davis e colaboradores (2014), os MCE têm o potencial de promover a aprendizagem dos estudantes, na medida em que incrementam o conhecimento dos professores e informam as suas práticas. Em relação aos professores, Gonzalez e colaboradores (2013) destacam a contribuição dos MCE para o desenvolvimento profissional em termos de atualização e projeção social. A aprendizagem do professor está relacionada ao desenvolvimento e à integração, em termos de ensino e aprendizagem, do quadro de conhecimento sobre os conteúdos a serem ensinados, que deve orientar, no contexto real de ensino, o planejamento e a prática docente (DAVIS; KRAJCIK, 2005). Segundo Davis e Krajcik (2005), esse movimento pode resultar em melhoria na participação no discurso de ensino, na enculturação e no engajamento na prática de ensino.

A utilização dos MCE orienta os professores tanto no sentido de ampliar o conhecimento a respeito da tomada de decisão em situações particulares como para desenvolver um conhecimento mais generalizável que possa ser aplicável a novas situações (DAVIS; KRAJCIK, 2005). A construção e o uso desses materiais dependem da proposta de ensino adotada pelo professor, principalmente no que tange a uma aprendizagem direcionada para a formação integral do estudante. Nesta perspectiva, os MCE devem ser produzidos levando em consideração o desenvolvimento de diversas habilidades e apropriação das dimensões conceitual, procedimental e atitudinal dos conteúdos (ARAN, 2001). E mais: da nossa perspectiva, os MCE devem ser uma ferramenta hábil e efetiva para que professores possam orientar a si e aos estudantes no planejamento, na execução e no acompanhamento/monitoramento de ações sociopolíticas executadas por eles. Ainda, é importante que esses materiais apresentem orientações teóricas que, sistematicamente, explicitem as razões racionais para as apostas que, neles, são feitas, bem como indicações sobre a maneira como os professores podem incorporar as apostas em suas salas de aula (DAVIS et al, 2014).

Vale salientar que, em virtude do aporte teórico metodológico usado neste trabalho ser a pesquisa de design educacional, é importante que a construção dos MCE esteja apoiada numa compreensão teórica de seus objetivos, associada com o conhecimento experiencial (conhecimento docente) sobre práticas bem sucedidas. Assim, a cada ciclo de prototipagem, há um refinamento em termos de planejamento embasado por resultados de investigação empírica. 


\section{Resultados preliminares: construção do quadro teórico e sistematização dos princípios de design}

Nesta seção, apresentaremos o quadro teórico que orientou a sistematização dos $\mathrm{PrD}$, os quais são caracterizados em seguida. $\mathrm{O}$ quadro teórico foi construído a partir do diálogo entre literatura pertinente e o conhecimento docente da equipe que desenvolve a pesquisa.

\section{Orientações para a construção de uma inovação educacional contextualizada por uma abordagem CTSA}

O Ensino de Ciências tem a sua importância atrelada a sua potencialidade de tornar os estudantes cidadãos mais críticos e autônomos, especialmente no que diz respeito a questões sociocientíficas (SADLER, 2005; KOLSTØ et al, 2006). Assumimos, aqui, a perspectiva que cidadania implica em participação política, ativismo e engajamento cultural. O cidadão deve ser, portanto, percebido de forma global, bem como deve ser um agente social responsável (GIROUX, 2004). Por isso suas decisões precisam ser tomadas levando em consideração não somente o bem individual, mas também a coletividade (SANTOS; MORTIMER, 2001).

Entretanto, o ensino promovido no ambiente escolar, em geral, não tem alcançado os seus objetivos, pois nem sempre possibilita que os estudantes se apropriem dos conceitos científicos de forma a utilizá-los para além das situações de ensino e aprendizagem escolares (PEDRANCINI et al. 2007), como por exemplo, na resolução de problemas do seu quotidiano. Quando demandamos que o Ensino de Ciências amplie a compreensão da realidade pelo estudante, atuando como uma ferramenta para orientar as suas decisões e intervenções no mundo que o cerca, não é interessante que os conteúdos sejam apenas "transmitidos" ou memorizados, mas efetivamente aprendidos de forma a serem aplicados em diferentes contextos (SARMENTO et al, 2013). Isto aponta na direção da necessidade de ir além da dimensão conceitual dos conteúdos, passando pelas dimensões procedimentais e sobretudo atitudinais dos conteúdos da educação científica (CONRADO; NUNES-NETO, 2018). Fica evidente, assim, a necessidade do currículo escolar de ciências voltar-se para ação social responsável, na qual existe uma preocupação com a formação de atitudes e valores (SANTOS; MORTIMER, 2001). Desta maneira, o Ensino de Ciências precisa promover uma leitura crítica da realidade. Para tanto, faz-se necessário que haja uma compreensão crítica das interações CTSA, levando em conta que a dinâmica da sociedade contemporânea é fortemente condicionada pela ciência e tecnologia (MUENCHEN; AULER, 2007).

Para Santos (2007), uma abordagem contextualizada por CTSA deve partir de problemas reais a fim de que os estudantes busquem o conhecimento científico para que possam entendê-los e solucioná-los. A introdução de QSC no ensino de ciências, a partir dos inícios dos anos 1980 (PÉREZ, 2012), devido a preocupações acerca da introdução de dimensões éticas da ciência, raciocínio moral e desenvolvimento emocional na educação científica, indica uma evolução progressiva da agenda CTSA, visto que esses dois movimentos têm objetivos semelhantes: o desenvolvimento psicológico, social e ético dos estudantes (SADLER et al, 2007).

Consideramos que QSC podem ser uma poderosa ferramenta para um ensino de Ciências de modo a favorecer o desenvolvimento de uma abordagem curricular CTSA. Pensamos, assim como Bossér e colaboradores (2015), que as QSC têm o potencial de criar 
condições para que os estudantes desenvolvam a capacidade de participação, de maneira responsável, nas mudanças sociais. Favorece, portanto o desenvolvimento da cidadania, sempre buscando o que é certo, bom e justo para todos (HODSON, 2013). As QSC permitem que os estudantes analisem criticamente as vantagens e desvantagens dos avanços científicos e tecnológicos, tanto em termos individuais quanto coletivos, e podem contribuir para que sejam mobilizados conhecimentos de ética no sentido de desenvolver habilidades para a tomada de decisão (GUTIEREZ, 2015).

Outro fator que influencia positivamente o uso de QSC é o potencial que apresentam para promover uma abordagem mais abrangente dos conteúdos da ciência escolar, considerando as suas três dimensões: conceituais, procedimentais e atitudinais (CPA) (CONRADO; NUNES-NETO, 2015). A dimensão conceitual está associada a uma perspectiva epistemológica, indicando o que se deve saber, ou seja, relacionada aos conceitos, princípios, bem como compreende a memorização de fatos e evidências. A dimensão procedimental está atrelada a uma perspectiva metodológica, apontando para o que se deve saber fazer. Dito de outra maneira, essa dimensão ocupa-se dos conteúdos relativos a procedimentos e aplicação de técnicas e métodos. Por fim, a dimensão atitudinal traz uma perspectiva axiológica, contemplando reflexões sobre o que se deve ser, sobretudo com base na filosofia moral, sendo, no caso da educação científica, considerado os aspectos ambientais, políticos e éticos das ciências (CONRADO; NUNES-NETO, 2018; ZABALA, 1998).

Segundo Reis (2013), as QSC não são resolvidas apenas com base na técnica, sendo necessário considerar hierarquia de valores, problemas financeiros e problemas sociais. Este argumento é reforçado por Sadler e Zeidler (2004), que afirmam que a resolução das QSC envolve a mobilização de dimensões morais e éticas. Assim, o uso de QSC, para a implementação de uma abordagem contextualizada CTSA, possibilita o letramento científico dos estudantes de forma que estes estejam comprometidos com ações sociopolíticas e sejam capazes de tomar decisões responsáveis, apropriadas e eficazes, considerando os interesses sociais, econômicos, ambientais e moralmente éticos (HODSON, 2003).

Hodson (2003) propõe que haja uma combinação criteriosa das práticas locais; regionais, nacionais e globais que podem ser abordadas, no currículo, em quatro níveis de sofisticação (HODSON, 2003; HODSON, 2018), abordando: o entendimento, por parte dos estudantes, das complexas relações entre ciência, tecnologia, sociedade e ambiente; a compreensão de que decisões sobre o desenvolvimento científico e tecnológico são tomadas mediante interesses particulares, que trazem benefícios para uma minoria; $o$ empoderamento do estudante para ser capaz de desenvolver um próprio ponto de vista e posições de valores; a implementação de ações sociopolíticas, resultando na formação de ativistas

Esse modo de educar, direcionado para o ativismo, coaduna com a ideia de que a educação científica é um potencial vetor para que haja uma resposta para as profundas injustiças sociais e ambientais existentes no mundo, configurando-se como uma alternativa para que o ensino de ciências se mova na direção de uma educação voltada para a ação sociopolítica. Isso é importante para mudar o cenário atual de como a ciência é apresentada, servindo prioritariamente aos interesses daqueles que detém o capital (ALSOP; BENCZE, 2009). 
Com intuito de promover a oportunidade dos estudantes adquirirem mais experiência no planejamento, na execução e na avaliação da ação sociopolítica, Hodson (2011) propõe que a abordagem seja realizada em três fases: modelagem; prática guiada e aplicação. Na modelagem, o professor mostra e explica qual o comportamento desejado e fornece alguns exemplos. Enquanto, na prática guiada, o professor atua no apoio dos estudantes, os quais, por sua vez, adquirem mais autonomia para realizar as tarefas dentro de uma ação global. Por fim, na aplicação, os estudantes são protagonistas, realizando a ação independentemente do professor.

Este autor considera que a partir da observação e a ajuda do professor ou outros especialistas, o estudante pode aprender como se engajar na ação, praticar várias subhabilidades sob condições controladas, adquirindo níveis crescentes de responsabilidades no planejamento e organização da ação. Os feedbacks avaliativos e do confronto com as opiniões de outros intergrupos fazem com que o estudante reflita acerca dos seus posicionamentos. O professor é responsável por planejar as ações e direcionar as ações dos estudantes. Entretanto, à medida que os estudantes atingem a independência intelectual, eles assumem a responsabilidade sobre a sua aprendizagem e começam a planejar, executar e relatar seus próprios projetos. A assistência do professor deve permitir que os estudantes se movam no sentido de ir além do que eles aprenderam e usem seus conhecimentos e habilidades de forma criativa, para abordar questões diferentes, resolvendo novos problemas e construir uma nova compreensão (HODSON, 2011). É evidente que essas atividades só serão produtivas se professores e estudantes forem capazes de estabelecer uma comunidade de aprendizagem caracterizada pelo respeito à diversidade, confiança, vontade de se envolver na aprendizagem colaborativa e vontade de contribuir para a aprendizagem de todos os membros da comunidade.

\section{Orientações para o ensino de ética na educação científica}

Em geral, o ensino de ciências tem formado pessoas que acreditam que a ciência e a tecnologia são tão eficientes em manipular e controlar o mundo que são capazes, por si só, de resolver os problemas da humanidade. Além de ser uma perspectiva ingênua, isto resulta numa passividade diante dos problemas socioambientais, não possibilitando a mudança do pensamento, atitudes e valores éticos (LOPES; COSTA, 2013). A escola, em virtude do seu papel na formação e na instrumentalização dos princípios éticos que orientam a sociedade, não pode se ausentar do debate ético (BRUM; SCHUHMACHER, 2014), que deve estar expresso em situações reais, nas quais os estudantes possam desenvolver a capacidade de analisar e eleger valores para si de forma livre e consciente (LODI; ARAÚJO, 2007). Esse debate precisa contemplar os valores humanos envolvidos nas questões relacionadas a esses problemas (NUNES-NETO, 2015), uma vez que os problemas ambientais possuem natureza, causas, soluções e implicações multidimensionais: econômicas, tecnológicas, éticas etc. (JAMIESON, 2010).

A ética, como um estudo racional dos valores e ações, do ponto de vista normativo, é o próprio campo de estudo de tais objetos, que podem ser concebidos como parte do conteúdo, levando em conta as dimensões CPA (CONRADO; NUNES-NETO, 2018). A formação integral dos estudantes é favorecida por meio de uma abordagem contextualizadora que mobilize as dimensões CPA do conteúdo, a fim de desenvolver habilidades referentes a: aquisição do conhecimento científico e tecnológico para resolução dos problemas do cotidiano; percepção dos interesses dos grupos e valores envolvidos na atividade científica; participação na resolução de problemas e proposição de ações sociopolíticas (CONRADO et al., 2016). 
Para Singer (1994), a ética aplicada consiste num campo da filosofia que utiliza a argumentação como instrumento para tratar dos grandes problemas da humanidade, visto que na maior parte das escolhas humanas há ramificações éticas. Jones (1991) afirma que muitas decisões são morais porque têm um componente moral, sendo o agente moral a pessoa que toma a decisão, mesmo que não reconheça que existem questões morais envolvidas. Este mesmo autor define que uma decisão ética é uma decisão moralmente aceitável para um maior número de pessoas. Desta maneira, na maioria das escolhas, existe um componente ético. Logo, estas escolhas são resultado, pelo menos em parte, de uma ação moral.

É importante salientar que os modelos éticos são relacionais, pois há o objetivo de estabelecer relações apropriadas entre os sujeitos morais e uma entidade. Então, o estabelecimento de uma ética relacional implica normalmente: (1) no estabelecimento de relações entre agente moral e outra entidade; (2) uma ideia da ontologia da outra entidade e (3) a noção de valor da outra entidade (SILVA, 2012).

O ensino explícito de ética focado nas perspectivas da ontologia moral dá uma ênfase especial para quais seres ou entidades são considerados moralmente em cada uma das correntes: antropocentrismo, antropocentrismo seletivo, senciocentrismo, biocentrismo e ecocentrismo. A partir da caracterização das correntes de ontologia moral, é possível notar uma ampliação da consideração moral, partindo do antropocentrismo seletivo até o ecocentrismo.

O antropocentrismo é a perspectiva de ontologia moral segundo a qual apenas seres humanos são dignos de consideração moral. Ou seja, qualquer ser que não pertença à espécie humana não precisa ser considerado moralmente (CONRADO, 2017). Em outras palavras, uma vez que só os seres humanos são considerados moralmente, só eles, então, têm valor intrínseco, ou seja, todos os outros seres, incluindo animais não humanos, plantas, outros seres vivos, têm valor meramente instrumental. $\mathrm{O}$ antropocentrismo não é perfeito na sua delimitação da comunidade moral como sendo apenas composta por seres humanos. As pessoas não são antropocêntricas de forma perfeita. Elas incluem alguns não humanos que interessam para elas, os quais respeitam e protegem, como por exemplo o animal de estimação que é protegido como uma criança no núcleo da família. Contudo, alguns humanos não são considerados como deveriam. O que se verifica, então, é um antropocentrismo seletivo em que só alguns seres humanos são dignos de consideração moral (VAZ; DELFINO, 2010; CONRADO; EL-HANI; NUNES-NETO, 2013). Muitas vezes a exclusão da consideração moral leva em conta critérios que são mais excludentes do que a espécie humana tais como: posição social, grupo étnico racial, região geográfica, religião, gênero etc. Assim, mais seres humanos são colocados para fora da fronteira da consideração moral.

Pensar num Princípio da Igualdade entre humanos e animais não implica na necessidade de tratá-los exatamente da mesma forma, ou conceder os mesmos direitos. $\mathrm{Na}$ verdade, depende da natureza dos membros de cada um dos grupos. Logo, o princípio de igualdade não requer tratamento idêntico, mas em verdade exige consideração igual. A consideração está associada à preocupação com o bem-estar do outro e, de acordo com o princípio da igualdade, tal cuidado deve ser ampliado para todos os seres humanos e não humanos sencientes (SINGER, 1975). Tal característica oportuniza, aos seres sencientes, o direito a uma consideração moral igual. Portanto, o limite da senciência é a única fronteira, minimamente, defensável de preocupação aos interesses dos outros. 
O biocentrismo é uma perspectiva de ontologia moral que designa que os seres vivos devem ser considerados moralmente, isto inclui os humanos e não-humanos. Numa perspectiva biocêntrica, a forma de agir com relação às coisas vivas depende da preocupação que se tem para com elas e de qual relação é estabelecida com elas. Assim, a ontologia moral biocêntrica está pautada em quatro premissas básicas a saber: (1) o ser humano é membro da comunidade viva terrestre, do mesmo modo que qualquer outro ser vivo; (2) os seres vivos humanos e não-humanos são elementos integrais num sistema de interdependência, tal que a sobrevivência e bem-estar de cada ser vivo não depende, somente, das condições físicas ambientais mas também de suas relações com outros seres vivos; (3) cada indivíduo é único na busca de seu próprio bem por meio de seus próprios caminhos; (4) o ser humano não é inerentemente superior aos outros seres vivos. (TAYLOR, 1981) Segundo Felipe (2009), no biocentrismo, a comunidade moral é formada por agentes e pacientes morais e não, apenas, por agentes morais racionais como se dá no antropocentrismo. Tanto os animais quanto as plantas, bem como qualquer outro ser vivo que possua interesse em seu bem-estar e desenvolvimento, possui valor intrínseco (BECKERT, 2004; VAZ; DELFINO, 2010). Nessa perspectiva, há uma obrigação moral dos agentes morais para com todos os outros seres vivos (FELIPE, 2009). O raciocínio ético biocêntrico orienta a atribuição de direitos a todos os indivíduos.

O ecocentrismo é uma reorientação da perspectiva moral, na qual o não-humano (mundo natural) e elementos abióticos deixam de ser concebidos como instrumentos para satisfazer os interesses humanos e passam a ser tratados como entidades com a quais os humanos devem ter responsabilidade. A perspectiva ecocêntrica está centrada nas totalidades ecológicas (VAZ; DELFINO, 2010; CONRADO; EL HANI; NUNES-NETO, 2013; NUNES-NETO, 2015). Há, portanto, a ampliação da consideração moral para entidades ambientais coletivas, como espécies e ecossistemas, inclusive elementos abióticos.

\section{O uso de textos de divulgação científica}

Para orientar a construção de uma sequência didática, da nossa perspectiva, sobre o tema, textos de divulgação científica (TDC) podem ser ferramentas adequadas. De acordo com Nascimento e Alvetti (2006), os TDC são capazes de proporcionar motivação e estímulo à participação dos estudantes. Sarmento e colaboradores (2013) apontam que os TCD cumprem bem a função de contextualizar o tema e mobilizar as discussões sobre questões específicas acerca do conteúdo que está sendo ensinado. Desse modo, a aula fica mais dinâmica e interessante para os estudantes, e com um grande potencial de melhorar a compreensão dos conteúdos trabalhos em sala.

Além disso, Batistele e colaboradores (2018), em sua revisão sobre uso de TDC em atividades didáticas, evidenciam que os TCD são usados com a finalidade de favorecer a construção do conhecimento científico, contribuindo para apropriação do conhecimento sobre natureza da ciência e a melhoria da capacidade de argumentação. Acreditamos que a compreensão da natureza da ciência, e mais especificamente das características da ciência, e o desenvolvimento da capacidade da argumentação, contribuem para a construção de uma visão mais informada da ciência, dando maior possibilidade, aos estudantes, de utilizarem o conhecimento científico na tomada de decisão para resolução de problemas relacionados com questões socioambientais (SERRA, 2012; CONRADO, 2017).

Segundo Paiva (2019), na educação básica, além complementar os recursos didáticos, os TDC podem ter objetivos formativos, tais como o desenvolvimento do 
pensamento crítico, o estimulo à busca pelo conhecimento científico, a apropriação de terminologias e conceitos científicos, o desenvolvimento de habilidades de leitura, interpretação e domínio de conteúdos. No Brasil, os PCNEM discutem que habilidades para obter, sistematizar, produzir e mesmo difundir informações são imprescindíveis para lidar com a grande quantidade de informações disponíveis nos dias de hoje, "aprendendo a acompanhar o ritmo de transformação do mundo em que vivemos" (BRASIL, p. 27, 2000).

Segundo Loiola e colaboradores (2013), um fator relevante para o uso de TDC no ensino de ciências diz relação ao gênero de discurso que apresentam, muito próximo ao que é utilizado pelos estudantes em seu cotidiano, o que tem o potencial de apoiar o desenvolvimento do discurso da ciência escolar. Essa aproximação com o universo linguístico dos estudantes facilita a compreensão dos conteúdos da ciência escolar uma vez que faz a transposição de uma linguagem científica mais complexa para uma linguagem mais simples e didática.

Martins e colaboradores (2004) fizeram um estudo acerca de trabalhos que utilizam tais textos nos espaços escolares e concluíram que há um crescente interesse da comunidade científica em pesquisar o funcionamento dos textos de divulgação científica em relação a várias perspectivas. O estudo de Martins e colaboradores (2004) concluiu que a divulgação científica tem o potencial de beneficiar o processo de ensino e aprendizagem uma vez que coloca à disposição de professores e estudantes uma riqueza de tipos diferentes de argumentos sobre temas recentes da ciência e da tecnologia de forma contextualizada com o cotidiano da sociedade contemporânea.

\section{A importância da caracterização do contexto escolar}

De acordo com a pesquisa de design educacional, a caracterização do contexto escolar e dos estudantes é importante tanto para a sistematização dos PrD e a construção de uma SD quanto para a interpretação dos dados obtidos a partir da sua implementação de modo a produzir evidências generalizáveis para outros contextos. É importante também para que outros professores possam avaliar se há similaridades com os contextos em que ensinam que justifiquem a transposição dos $\operatorname{PrD}$ para suas práticas.

Portanto, elaboramos um questionário socioeconômico e sociocultural, levando em consideração as dimensões pessoal, escolar, sociocultural e socioeconômica dos estudantes, além de suas atitudes individuais acerca das questões ambientais. $\mathrm{O}$ questionário socioeconômico foi construído por dois professores pesquisadores autores deste trabalho. Em seguida, foi enviado para uma pesquisadora, também autora deste trabalho, a fim de avaliar a clareza e a pertinência do instrumento aos seus objetivos de pesquisa. A análise feita pela pesquisadora possibilitou o refinamento e a adequação do instrumento para o contexto do estudo e para os dados que se pretendia coletar.

Os resultados parciais apresentados nesse artigo contribuíram para a elaboração de uma SD para ser implementada na primeira série do ensino médio do Colégio da Polícia Militar da Bahia (CPM), unidade Dendezeiros, situado no município de Salvador, em área pertencente ao Complexo da Vila Policial Militar do Bonfim. É um colégio de grande porte, que ministra aulas para o Ensino Fundamental I, Ensino Fundamental II e Ensino Médio. Atualmente, o colégio funciona nos turnos matutino e vespertino e o ensino é ministrado gratuitamente. Até 1994, o colégio apenas atendia a estudantes do sexo masculino, mas a partir desse ano passou a aceitar também estudantes do sexo feminino. $\mathrm{O}$ CPM é uma unidade escolar cuja estrutura organizacional é constituída por um modelo de gestão partilhado pela Polícia Militar da Bahia e pela Secretaria de Educação do Estado. 
Desta forma, a direção geral do colégio é constituída por duas diretorias: (1) diretoria da Polícia Militar e (2) diretoria da Secretaria de Educação do Estado. Em 2018, O CPMDendezeiros teve o ensino médio modificado de acordo com a reforma do EM. O novo EM ficou composto pela Base Nacional Curricular Comum (BNNC) e pelos Itinerários Formativos (IF). A BNCC contempla 1800 horas, sendo 600 horas em cada série (primeira, segunda e terceira séries), sendo composta pelas seguintes disciplinas: Língua Portuguesa (LP), Língua Estrangeira (LE), Matemática, Artes, Biologia, Química, Física, História, Geografia, Sociologia, Filosofia, Educação Física. Os IF contemplam 1200 horas, sendo 400 horas em cada série (primeira, segunda e terceira séries). Assim, cada série apresenta um total de 1000 horas em 200 dias letivos.

Atualmente, o CPM - Dendezeiros tem 1687 estudantes matriculados. Na primeira série do ensino médio, estão matriculados 180 estudantes. Destes, 119 responderam o questionário socioeconômico. Segundo os dados do questionário, os estudantes que responderam o questionário têm, em sua maioria, idades entre 14, 15 e 16 anos (88\%). Em relação ao sexo, a proporção é muito parecida, sendo $51 \%$ do sexo masculino e $47 \%$ do sexo feminino. Os $2 \%$ restantes não responderam. Acerca da naturalidade, $94 \%$ dos estudantes nasceram em salvador e $99 \%$ residem neste município.

As respostas sobre a vida escolar dos estudantes nos possibilitaram inferir que a maioria deles, cerca de 85,71\%, cursou o Ensino Fundamental (do 6 ao 9 ano) no CPM Dendezeiros. A partir das respostas ao questionário, foi possível inferir que os pais participam da vida escolar dos estudantes, indicando que maioria acompanha o rendimento dos filhos (80,67\%). Cerca de 46,22\% dos pais auxiliam seus filhos nos estudos, 45,38\% vão à escola, sempre que necessário, para conversar com coordenadores e esclarecer dúvidas e 58,82\% participam das reuniões escolares.

Sobre o motivo pelo qual eles estudam no CPM - Dendezeiros, 42,02\% dos estudantes responderam que estudam no CPM - Dendezeiros porque os pais querem e/ou gostam da estrutura da escola. Outros motivos também foram mencionados tais como: o CPM apresenta um bom ensino $(31,93 \%)$, gostam da escola $(16,81 \%)$ dentre outros. A maioria dos estudantes $(90,76 \%)$ concordou que o estudo da Biologia é importante. De acordo com as respostas, as fontes de pesquisa mais utilizadas para estudar são: livros didáticos fornecidos pela escola $(70,59 \%)$, enciclopédia virtual $(56,30 \%)$, anotações manuais das aulas $(77,31 \%)$, blogs e sites em geral $(67,23 \%)$, vídeo-aula e vídeos obtidos na Internet $(85,71 \%)$ e busca na internet $(87,39 \%)$. Estes dados indicam a importância do livro didático fornecido pela escola e das tecnologias de informação e comunicação como ferramentas de apoio à aprendizagem dos estudantes. Quando perguntados sobre as fontes que usam para ter acesso a informações, $61,34 \%$ dos estudantes responderam que usam TV aberta, 57,14\%, TV por assinatura, 96,64\%, internet e 64,71\%, livros. A maioria dos estudantes $(75,63 \%)$ afirmou que lê notícias relacionadas aos avanços científicos, os demais $21,85 \%$ não lê e $2,52 \%$ não responderam.

Em relação às atitudes individuais, os dados do questionário nos permitiram inferir que os estudantes estão preocupados com o impacto das suas ações no meio ambiente, uma vez que $37,82 \%$ afirmam que separam o lixo, $24,37 \%$ reduziram o consumo de produtos poluentes, $18,49 \%$ fazem reciclagem do lixo, $31,43 \%$ reduziram o consumo de produtos industrializados, $35.29 \% \%$ fazem o consumo consciente de produtos de origem animal, $89.08 \%$ fazem uso consciente da água, $32.77 \%$ buscam conscientizar as pessoas sobre problemas ambientais por meio de conversas, blogues, postagens em redes sociais etc., $8.40 \%$ se envolvem nos problemas da comunidade buscando soluções junto a líderes

Revista Educação e Fronteiras On-Line, Dourados/MS, v.9, n.25, p. 183-207, jan./abr. 2019. 
políticos, $13,45 \%$ participam de grupos de ativismo social, a exemplo movimentos feministas, movimentos de apoio às causas LGBTs e de combate ao feminicídio, contra racismo e homofobia, e contra o sofrimento animal. Além disso, apenas 4,20\% responderam que não realizam nenhuma das ações elencadas no questionário, o que apoia a ideia de que os estudantes realizam ações visando minimizar o seu impacto no meio ambiente. Eles acreditam que tanto ações individuais (70.59\%), quanto sociais (69.75\%), governamentais $(65.55 \%)$ e globais $(73.11 \%)$ são necessárias para minimizar o aquecimento global. No que diz respeito às causas das mudanças climáticas, a maioria (89.08\%) afirma que as ações humanas são responsáveis pela degradação do ambiente natural provocando o aquecimento global. Somente 5,04\% apontou que o aquecimento global tem causas naturais e por isso não existe ações realizadas pelo ser humano que possa mitigá-lo.

\section{Sistematização dos princípios de design}

A partir dos resultados apresentados neste trabalho (quadro teórico) podemos construir uma SD, com base em PrD, Para isso, seguimos a fórmula geral adaptada de Van den Akker (SARMENTO, 2016):

Se vocề deseja construir uma intervenção $\mathrm{X}$ para o propósito/função $\mathrm{Y}$ em um contexto Z, é aconselhável:

(1) Adotar a característica A, para o propósito/função y1, realizando o procedimento $\mathrm{K}$, em razão do argumento $\mathrm{P}$.

(2) Adotar a característica $\mathrm{B}$, para o propósito/função y2, realizando o procedimento L, em razão do argumento Q.

(3) Adotar a característica $\mathrm{C}$, para o propósito/função y3, realizando o procedimento M, em razão do argumento R. (...)

Assim, em síntese, para o planejamento da SD, usamos alguns princípios, sistematizados a seguir:

Para construir uma sequência didática sobre aquecimento global para fomentar as dimensões conceituais, procedimentais e atitudinais (CPA) dos conteúdos científicos para ações sociopolíticas em estudantes da primeira série do EM, é importante incluir na intervenção:

i. Um enfoque sobre ética, incorporando uma abordagem que considera as diferentes perspectivas acerca da ontologia moral, com intuito de que o estudante amplie sua consideração moral e possa tomar decisões informadas pela ciência, mas também fundamentadas em princípios e argumentos éticos. A implementação desse enfoque pode ser realizada por meio de uma abordagem explícita sobre ética. As razões que determinaram esse enfoque em ética são: (1) Os problemas ambientais são multidimensionais, sendo necessário um debate sobre ética que transpasse todos os propósitos humanos envolvidos nestes problemas; (2) Os princípios éticos devem estar expressos em situações reais, nas quais os estudantes possam desenvolver a capacidade de analisar e eleger valores para si de forma livre e consciente; (3) a degradação ambiental se deve ao fato de vivermos sob a égide de uma ética antropocêntrica, na qual o sistema de valores coloca o homem no centro de todas as coisas e (4) os problemas ecológicos reclamam uma resposta ética, no sentido de mudança de identidade dos cidadãos e da forma como se relacionam com a natureza.

ii. Uso de uma abordagem integrada HFC/CTSA, visando a formação de cidadãos mais autônomos e críticos, capazes de tomar decisões e implementar 
ações sociopolíticas socialmente mais justas e ambientalmente sustentáveis. A implementação dessa abordagem pode ocorrer por meio do uso de QSCs que envolvem os conhecimentos sobre capitalismo, ética ambiental e animal e crise ambiental e por meio da discussão de aspectos controversos acerca do aquecimento global. Escolhemos usar uma abordagem integrada HFC/CTSA, pois apostamos num ensino de ciências contextualizado capaz de refletir a dinâmica de interação entre a ciência e a sociedade, abordando os aspectos científicos de determinadas questões relacionadas aos avanços tecnológicos e da ciência, e também os sociais, políticos, econômicos, ambientais e morais. Para implementar a abordagem CTSA, escolhemos as QSCs, uma vez que apostamos nestas como poderosas ferramentas com o potencial de: (1) criar condições para que os estudantes desenvolvam a capacidade de serem participantes responsáveis nas mudanças sociais, sempre na busca do o que é certo, bom e justo para todos; (2) desenvolver o pensamento crítico dos estudantes, permitindo que analisem criticamente as vantagens e desvantagens dos avanços científicos e tecnológicos, tanto em termos individuais quanto coletivos; (3) contribuir para que sejam mobilizados, pelos estudantes, conhecimentos de ética no sentido de desenvolver habilidades para a tomada de decisão (4) promover uma abordagem mais abrangente dos conteúdos da ciência escolar considerando as dimensões CPA.

iii. O uso de textos de divulgação científica (TDC), para contextualização e sistematização do processo de construção do conhecimento científico sobre capitalismo e a sua relação com a ética e o aquecimento global, implementado por meio de leitura e discussão, em pequenos grupos de estudantes. No caso específico do nosso trabalho, usaremos resumos de dois capítulos do livro organizado por José Eli da Veiga (Aquecimento global: frias contendas científicas, 2008. Capítulo 2: Base científica para a compreensão do aquecimento global, por Sonia Barros de Oliveira; Capítulo 3: Aquecimento global: uma visão crítica, por Luiz Carlos Baldicero Molion), adaptado ao contexto de aplicação. No entanto, outros textos poderçao se mostrar mais adequados a contextos de ensino distintos daquele no qual conduzimos o nosso estudo por razões psicocognitivas e didáticas. Escolhemos usar TDC porque a literatura sobre ensino de ciências tem discutido seu potencial para motivar os estudantes, promover debates, apresentar fontes de curiosidade, além de contextualizar os conceitos científicos que se deseja ensinar em relação ao cotidiano dos estudantes. Além disso, temos utilizado esses instrumentos de divulgação da ciência como estratégias de contextualização dos conceitos científicos trabalhados em sala e de motivação e estímulo à participação dos estudantes, com bastante sucesso.

iv. Em acordo com a perspectiva colaborativa e de uma educação para formar agentes altruístas - algo que permeia todo este trabalho - contamos com um processo coletivo e cooperativo de aprendizagem. Tal princípio apresenta o potencial de auxiliar na construção dos conceitos, no plano social da sala de aula, mediados pela linguagem, a partir da implementação de atividades de interação e discussão em pequenos grupos de estudantes, mediados pelo professor, em virtude de uma decisão metodológica de tomar como pressuposto para a construção da sequência didática uma visão sociocultural de 
aprendizagem. Esta se fundamenta na ideia de que as funções mentais superiores, a exemplo da formação dos conceitos, ocorrem primeiro no plano social, como uma categoria interpsicológica, e, após a internalização de experiências vivenciadas socialmente, torna-se uma categoria intrapsicológica, sendo que as relações entre estas duas categorias são mediadas por signos construídos social e culturalmente, a exemplo da linguagem.

\section{CONSIDERAÇÕES FINAIS}

Considerando a crise socioambiental contemporânea e as discussões neste artigo sobre a necessidade e a importância de desenvolvermos transformações no contexto da educação básica, visando a um ensino de ciências que possa contribuir para que os estudantes sejam capazes de tomar decisões informadas e responsáveis acerca dos desafios socioambientais atuais que ameaçam, inclusive, nossa sobrevivência como espécie no planeta, investimos esforços no estudo do contexto de ensino e na elaboração de PrD para uma $\mathrm{SD}$, os quais tenham o potencial de formar cidadãos capazes de usar o conhecimento científico para agir de forma consciente acerca da crise ambiental e construir estilos de vida mais sustentáveis do ponto de vista ambiental e de justiça social.

Para apoiar a elaboração dos $\mathrm{PrD}$, construímos um quadro teórico a partir do diálogo entre a literatura sobre ensino de ciências e o conhecimento docente, considerando uma perspectiva inter e transdisciplinar. Neste estudo, apresentamos o quadro teórico e os cinco PrD sistematizados. O primeiro princípio trata do ensino de ética, porque acreditamos que a crise ambiental é decorrente, em parte, da crise ética que a humanidade está vivendo e defende que a ética deve ser um conteúdo atitudinal atrelado ao ensino de todos os conteúdos conceituais de ciência. $\mathrm{O}$ segundo princípio defende uma abordagem $H F C$ e CTSA, pois o ensino de um tema como aquecimento global requer que os estudantes compreendam a relações CTSA e conheçam as características da ciência, de forma que se tornem mais autônomos e mais críticos para tomada de decisões informadas e responsáveis. O uso de vídeo e de textos de divulgação científica, terceiro e quarto princípios de design, tem a finalidade de motivar os estudantes e criar um ambiente propício para a discussão de assuntos como a relação do capitalismo, mídia e aquecimento global, bem como temas controversos, como, por exemplo, se o aquecimento global tem causas antrópicas ou naturais. O quinto princípio de design é o processo coletivo $e$ cooperativo de aprendizagem, que auxilia na construção dos conceitos, no plano social da sala de aula, mediados pela linguagem.

Em trabalhos futuros, apresentaremos a validação da SD, os resultados da sua investigação e os materiais curriculares educativos resultantes da sua implementação.

\section{REFERÊNCIAS}

ALMEIDA, M. C. Colaboração entre pesquisadores e professores de ensino de Ciências e Biologia: um estudo da organização e desenvolvimento social da prática social do grupo COPPEC. Dissertação de Mestrado do Programa de Pós-Graduação em Ensino, Filosofia e História das Ciências da Universidade Federal da Bahia. Salvador. 2014

ARAN, A. P. ¿ Servir al material o servirse del material? Evaluar los materiales curriculares para mejorar su uso. Kikiriki. Cooperación educativa n.61. p.44-49. 2001. 
BARNOSKY, D. A. et al. Has the Earth's sixth mass extinction already arrived? Nature. $\mathrm{n}$. 471, p. 51-57, March 2011.

BATISTELE, M. C. B. D, N. de P. OLIVEIRA, J. R, S. O uso de textos de divulgação científica em atividades didáticas: uma revisão. R. bras. Ens. Ci. Tecnol., Ponta Grossa, v. 11, n. 3, p. 182-210, set./dez. 2018

BECKERT, C. et al. Ética. Lisboa: Centro de Filosofia da Faculdade de Lisboa, 2012

BECKERT, C. Interesses e direitos: duas perspectivas sobre ética animal. In: BECKERT, C. VARANDAS, M. J. (orgs). Éticas e políticas ambientais. Lisboa: Centro de Filosofia da Universidade de Lisboa, 2004. p.37-58.

BENCZE. L. 'STEPWISE': Science \& Technology Education Promoting Wellbeing for Individuals, Societies \& Environments. 2014. Disponível em: <http://webspace.oise.utoronto.ca/\%7Ebenczela/STEPWISE_Sumry4Tchrs.pdf>

BENCZE, L.; ALSOP, S. Ecojustice through responsibilist science education. Annual Conference of the Canadian Society for the Study of Education. Ottawa, ON, May 23- 26, p. 1-14, 2009.

BENCZE, L.; ALSOP, S. Activism! Toward a More Radical Science and Technology Education. in: ALSOP, S.; BENCZE, L. Activist Science and Technology Education. Cultural Studies of Science Education, V. 9. London: Springer, p. 1-19, 2014.

BOSSÉR, U.; LUNDIN, M.; LINDAHL, M.; et al. Challenges faced by teachers implementing socio-scientific issues as core elements in their classroom practices. European Journal of Science and Mathematics Education. v. 3, n. 2, p.159-176, 2015.

BRASIL. Ministério da Educação, Secretaria de Educação Média e Tecnológica. Parâmetros Curriculares Nacionais: Ensino Médio. Brasília: Ministério de Educação, 2000.

BROWN A. L. Design Experiments: Theoretical and Methodological Challenges in Creating Complex Interventions in Classroom Settings. The jornal of the learning sciences. Madison, v.2, n.2, p.141-178, 1992.

BRUM, W. P; SCHUHMACHER, E. Ética no ensino de ciências: o posicionamento de professores de ciências sobre eticidade durante a abordagem do tema transgênicos e suas implicações socioambientais. Ens. Pesqui. Educ. Ciênc. Belo Horizonte, v. 16, n. 1, p. 189211, Apr. 2014.

COBB, P. et al. Design Experiments in Educational Research. Educational Researcher, v. 32, n.1, p.9-13, 2003.

CONRADO, D. M.; EL-HANI, C. N.; NUNES-NETO, N. F. Sobre a ética ambiental na formação do biólogo. Revista Eletrônica do Mestrado em Educação Ambiental (REMEA), v. 30, n. 1, p. 120-139, jan./ jun. 2013.

CONRADO, D. M., NUNES-NETO, N. F. Dimensões do conteúdo em questões sociocientíficas no ensino de ecologia. Atas do XVI ENEC - Encontro Nacional de Educação em Ciências Lisboa: APEduC. pp. 432-435. 2015. 
CONRADO, D. M; CONRADO, I.S. Análise crítica do discurso sobre imagens da ciência e da tecnologia em argumentos de estudantes de biologia. Revista Pesquisa Qualitativa. São Paulo (SP), v. 4, n. 5, p. 218-231, ago. 2016.

CONRADO, D. M. Questões Sociocientíficas na Educação CTSA: contribuições de um modelo teórico para o letramento científico crítico. 2017. 239 p. Tese de Doutorado. Programa de Pós-Graduação em Ensino, Filosofia e História das Ciências Universidade Federal da Bahia / Universidade Estadual de Feira de Santana. 2017.

CONRADO, D. M., NUNES-NETO, N. F. Questões Sociocientíficas: fundamentos, propostas de ensino e perspectivas para ações sociopolíticas. Salvador: EDUFBA, 573 p. 2018.

DAVIS, E. A.; KRAJCIK, J. Designing educative curriculum materials to promote teacher learning. Educational Researcher, v.34, n.3, p.3-14, 2005.

DAVIS et al. Designing Educative Curriculum Materials: A Theoretically and Empirically Driven Process. Harvard Educational Review, v.4, n.1, Spring, 2014.

DILLON, J. Science, Environment and Health Education: Towards a Reconceptualisation of Their Mutual Interdependences. In: ZEYER, A.; KYBURZ-GRABER, R. (Org.). Science, Environment, Health: Towards a Renewed Pedagogy for Science Education. London: Springer, p. 87-101, 2012.

EL-HANI, C. N. et al. A natureza da pesquisa docente: a experiência de um grupo colaborativo de pesquisa. Atas do VIII Encontro Nacional de Pesquisa em Educação em Ciências (ENPEC). Campinas: ABRAPEC, 2011.

FELIPE, S. T. Antropocentrismo, sencientismo e biocentrismo: perspectivas éticas abolicionistas, bem-estaristas e conservadoras e o estatuto de animais não-humanos. Revista Páginas de Filosofia, v.1, n.1, p.2-30, jan./jul., 2009.

GIROUX, H. A.; GIROUX, S. S. Challenging neoliberalism's new world order: the promise of critical pedagogy. Cultural Studies/Critical Methodologies, Oxfordshire, v. 6, p. 21-32, 2006.

GOnZÁleZ, G. T.; ESTRADA, F. J. P.; DE LEÓN, P. C. Análisis de materiales curriculares y práctica docente. Cuadernos de Pedagogía. n. 432 p. 51-53, 2013.

GOODLAND, R., ANHANG, J. Livestock and climate change. What if the key actors in climate change are cows, pigs and chickens? World Watch Institute. p. 10-19. 2009.

GUIMARÃES, A. P. M. et al. O aquecimento global como conteúdo norteador para ensinar sobre visão sistêmica do planeta terra no ensino médio. Atas do IX Encontro Nacional de Pesquisa em Educação em Ciências (ENPEC). Águas de Lindóia, SP: ABRAPEC, 2013. p. A0233-1.

GUTIEREZ, S. B. Integrating Socio-Scientific Issues to Enhance the Bioethical DecisionMaking Skills of High School Students. International Education Studies. Canadá, v. 8, n. 1, p. 142-151, 2015. 
HODSON, D. Time for action: Science education for an alternative future. International Journal of Science Education, 25, p. 645-670, 2003.

HODSON, D. Going Beyond STS: Towards a Curriculum for Sociopolitical Action. The Science Education Review. Austrália, v.3, n.1, p. 2-7, 2004.

HODSON, D. Looking to the Future: building a curriculum for social activism. Auckland: Sense. 2011.

HODSON, D. Don't Be Nervous, Don't Be Flustered, Don't Be Scared. Be Prepared. Canadian journal of science, mathematics and technology education. Canadá, v.13, n.4, p. 313-331, 2013.

HODSON, D. Realçando o papel da ética e da política na educação científica: algumas considerações teóricas e práticas sobre questões sociocientíficas. In: Questões Sociocientíficas: fundamentos, propostas de de ensino e perspectivas para ações sociopolíticas. Salvador: EDUFBA, 573 p. 2018.

IPCC. Climate Change 2014: Synthesis Report. Contribution of Working Groups I, II and III to the Fifth Assessment Report of the Intergovernmental Panel on Climate Change. IPCC, Geneva, Switzerland, 151p. 2014.

JACOBI, P. Educação ambiental, cidadania e sustentabilidade. Cad. Pesqui., São Paulo , n. 118, p. 189-206, Mar. 2003.

JAMIESON, D. Ética e meio ambiente: uma introdução. Tradução André Luiz de Alvarenga. São Paulo: SENAC, 2010.

JONES, T. M. Ethical decision making by individuals in organizations: An issuecontingent model. Academy of management Management Review, 366-395, 1991.

KRASILCHIK, M. Prática de Ensino de Biologia. 4.ed. São Paulo: EDUSP, 2008.

KOLLMUSS, A.; AGYEMAN, J. Mind the Gap: Why do people act environmentally and what are the barriers to pro-environmental behavior? Environmental Education Research, 8:3, 239-260, 2002.

KOLST $\varnothing$, S. D.; BUNGUM, B.; ARNESEN, E.; ISNES, A.; KRISTENSEN, T.; MATHIASSEN, K.; MESTAD, I.; QUALE, A.; TONNING, A. S. V.; ULVIK, M. Science students' critical examination of scientific information related to socio-scientific issues. Science Education, v. 90, p. 632-655, 2006.

LEFF, E. Epistemologia Ambiental. São Paulo: Cortez, 2006.

LODI, L. H.; ARAÚJO, U. F. Ética e Cidadania e Educação: Escola, democracia e cidadania. In: BRASIL. Ética e cidadania: construindo valores na escola e na sociedade. Brasília: Ministério da Educação, Secretaria de Educação Básica, 2007, p.69-84.

LOIOLA, L; ZANCUL, M. de S.; BIZERRIL, M. X. A. Uso de textos de divulgação científica no desenvolvimento de temas de Educação em Saúde na Educação de Jovens e Adultos (EJA). Atas do IX Encontro Nacional de Pesquisa em Educação em Ciências - IX ENPEC Águas de Lindóia, SP - 10 a 14 de Novembro de 2013. 
MAIA, M. M. D.; CABRAL, P. F. O.; QUEIROZ, S. L. Alimentação Saudável: abordagem interdisciplinar na educação básica. Educação e Fronteiras (online). v. 7, n. 21: p.14-24, 2017.

MARTINS, I.; NASCIMENTO, T. G.; ABREU, T. B. de. Clonagem na sala de aula: um exemplo do uso didático de um texto de divulgação científica. Investigações em Ensino de Ciências, V.9, n.1, p. 95-111, 2004.

MATTHEWS, M. R. Science Teaching: The Contribution of History and Philosophy of Science - 20th Anniversary Revised and Expanded Edition. New York: Routledge, 2014.

MOREIRA, H.A.. "Los materiales curriculares en los procesos de diseminación y desarrollo del currículum. In: ESCUDERO, J. Diseño, desarrollo e innovación del currículum. Síntesis, Madri. 2000.

MUENCHEN, C; AULER, D. Configurações curriculares mediante o enfoque cts: desafios a serem enfrentados na educação de jovens e adultos. Ciência \& Educação, v. 13, n. 3, p. 421-434, 2007.

MUNIZ, C. R. R. et al.Estudo de desenvolvimento de uma intervenção para o ensino de metabolismo energético - segundo protótipo. Atas do IV Encontro Nacional de Ensino de Biologia (ENEBIO) e II Encontro Regional de Ensino de Biologia (EREBIO). Goiânia: SBEnBIO, Regional 4, set., 2012.

NIEVEEN, N.; MCKENNEY, S.; VAN DEN AKKER, J. Educational design research: the value of variety. In: VAN DEN AKKER, J. et al. (Ed.). Educational design research. London: Routledge, 2006. p. 151-158.

NUNES-NETO, N. The Environmental Crisis as a Good Case for an Intellectual and Practical Integration Between Philosophy and Science. Book review of BERGANDI, Donato. The Structural Links Between Ecology, Evolution, and Ethics: The Virtuous Epistemic Circle. Dordrecht: Springer, 2013. Science and Education, 24: p.1285-1299, 2015.

PAIVA, A. Princípios de design para o ensino de biologia celular: pensamento crítico e ação sociopolítica inspirados no caso de Henrietta Lacks. Tese de Doutorado. Programa de Pós-Graduação em Ensino, Filosofia e História das Ciências Universidade Federal da Bahia / Universidade Estadual de Feira de Santana. 2019.

PEDRANCINI, V. D. et al. Ensino e aprendizagem de Biologia no ensino médio e a apropriação do saber científico e biotecnológico. Revista Electrónica de Enseñanza de las Ciencias, Vigo, v. 6, n. 2, p. 299-309, 2007.

PÉREZ, M. L. F. Questões sociocientíficas na prática docente: ideologia, autonomia e formação de professores. São Paulo: Unesp, 2012.

PLOMP, T. Educational design research: an introduction. In: PLOMP, T.; NIEVEEN, N. (Ed.). An introduction to educational design research. Enschede: Netherlands Institute for Curriculum Development, 2009. p. 9-35

REIS, P. Da discussão à ação sociopolítica sobre controvérsias sócio-científicas: uma questão de cidadania. Ensino de Ciências e Tecnologia em Revista. v. 3, n. 1. jan./jun. 2013. 
SÁ, T. S. et al.Energetic Metabolism in Biology Classrooms: A Developmental Study of a Teaching Sequence. Procedia: Social and Behavioral Sciences, v.167, p.50-55, 2015.

SADLER, T. D. Evolutionary theory as a guide to socioscientific decision-making. Journal of Biological Education, v. 39, n. 02, p. 68-72, 2005.

SADLER, T. D.; BARAB, S. A.; SCOTT, B. What Do Students Gain by Engaging in Socioscientific Inquiry? Science Education, v.37 n.4 p.371-391.2007

SADLER, T. D.; FOWLER, S. R. A threshold model of content knowledge transfer for socioscientific argumentation. Science Education. V.90, n.6, nov. 2006.

SADLER T. D.; ZEIDLER, D. L. The Morality of Socioscientific Issues: Construal and Resolution of Genetic Engineering Dilemmas. Science Education, jan. 2004.

SANTOS, W. L. P. Contextualização no ensino de ciências por meio de temas CTS em uma perspectiva crítica. Ciência \& Ensino. V.1, número especial, novembro de 2007.

SANTOS, W. L. P.; MORTIMER, E. F. Tomada de decisão para ação social responsável no ensino de ciências. Ciência \& Educação, v.7, n.1, p.95-111, 2001

SANTOS, W. L. P.; MORTIMER, E. F. Abordagem de aspectos sociocientíficos em aulas de ciências: possibilidades e limitações. Investigações em Ensino de Ciências. Porto Alegre, RS, v. 14, n. 2, p. 191-218, 2009.

SHARMA, Ajay. Mudanças climáticas globais: o que a educação científica tem a ver com isso? Science Education, v. 21, p. 33-53, 2012. DOI 10.1007/s11191-011-9372-1

SARMENTO, A. C. H. et al. Investigando princípios de design de uma sequência didática para o ensino sobre metabolismo energético. Atas do VIII Encontro Nacional de Pesquisa em Educação em Ciências (ENPEC). Campinas: ABRAPEC, 2011.

SARMENTO, A. C. de H. et al. Investigando princípios de design de uma sequência didática sobre metabolismo energético. Ciênc. educ. (Bauru), Bauru , v. 19, n. 3, p. 573598, 2013.

SARMENTO, A. C. de H. Como ensinar citologia e promover uma visão informada da ciência no nível médio de escolaridade. Dissertação (Mestrado em Ensino, Filosofia e História das Ciências - Linha de pesquisa: Ensino de Ciências). Universidade Federal da Bahia e Universidade Estadual de Feira de Santana. Salvador, 2016.

SERRA, H. Formação de professores e formação para o ensino de ciências. Educação $e$ Fronteiras, Dourados, v. 2, n. 6, p.24-36, 2012.

SILVA, J. M. Do Senciocentrismo ao Holismo Ético: perspetivas sobre o valor da bioesfera. In: Gravitações Bioéticas (A. Barbosa et al. eds.), p. 123 -145, 2012.

SIMONS, H.; KUSHNER, S.; JONES, K., JAMES, D. From evidence-based practice to practice- based evidence: the idea of situated generalization. Research Papers in Education, London, v. 18, n. 14, p. 347-364, 2003.

SINGER, P. Ética prática. São Paulo: Martins Fontes, 1994. 
SINGER, P. Animal liberation. The New York Review of Books, New York, 1975.

SOUSA, A. E. de A.; MUNIZ, C; SARMENTO, A.C. de H. O processo heurístico da construção do conceito de inovações educacionais por um grupo colaborativo de pesquisa. In: SEPULVEDA, C; ALMEIDA, M. (org.) Pesquisa Colaborativa e Inovações Educacionais no Ensino de Biologia. Feira de Santana: EdUEFS, 2016.

TAYLOR, Paul W. Respect for Nature: a theory of environmental ethics. Princeton, NJ: Princeton University Press, 1986 p., 2011.

THE DESIGN-BASED RESEARCH COLLECTIVE. Design-Based Research: An Emerging Paradigm for Educational Inquiry Educational Researcher, v. 32, n. 1, pp. 58.jan.2003

TRESS, B.; TRESS, G.; VAN DER VALK, A. Interdisciplinarity and transdisciplinarity in landscape studies - the Wageningen DELTA approach. 2003. Delta series 2, p. 8-15. Disponível em: https://pdfs.semanticscholar.org/3ba9/ 722cb4ced39b24ab9b372b6c1f2d8ecef26e.pdf?_ga=2.163483961.405481098.1569851072 -1633782787.1569851072. Acesso em: 30 de set. de 2019.

VAN DEN AKKER, J. Principles and Methods of Development Research. In J. van den Akker, R.M. et al (Eds), Design approaches and tools in education and training. Boston: Kluwer Academic, p.1-14, 1999.

VAZ, S. A. G.; DELFINO, Â. Manual de ética ambiental. Lisboa: Universidade Aberta, 2010.

VEIGA, J. E. (Org). Aquecimento global: frias contendas científicas. São Paulo: SENAC, 2008.

WWF. 2014. Living Planet Report 2014: People and places, species and spaces. [McLellan, R., Iyengar, L., Jeffries, B. and N. Oerlemans (Eds)]. WWF, Gland, Switzerland.

ZABALA, A. A. Prática educativa: como ensinar. Porto Alegre: Artmed, 1998.

Recebido em: 08/01/2019

Aprovado em: 10/06/2019 